\title{
Association of High Levels of Plasma Free Dopamine With Future Coronary Events in Patients With Coronary Artery Disease
}

\author{
Makoto Abe, MD; Masahiko Iwaoka, MD; Takamitsu Nakamura, MD; Yoshinobu Kitta, MD; \\ Hajime Takano, MD; Yasushi Kodama, MD; Kenichi Kawabata, MD; Jyun-ei Obata, MD; \\ Akira Mende, MD; Tsuyoshi Kobayashi, MD; Daisuke Fujioka, MD; \\ Yukio Saito, MD; Hideyuki Hasebe, MD; Kiyotaka Kugiyama, MD
}

\begin{abstract}
Background There is an intimate relationship between activation of the sympathetic nervous system and myocardial ischemia. This study examined whether plasma levels of dopamine, a precursor of norepinephrine, may provide prognostic information in coronary artery disease (CAD).

Methods and Results Plasma levels of free dopamine were measured by high-performance liquid chromatography in 210 consecutive patients with stable CAD. The patients were prospectively followed up for a period of $\leq 36$ months until occurrence of a clinical coronary event. Coronary events occurred in 37 patients during followup. In Kaplan-Meier survival analysis, higher dopamine levels $(\geq 30 \mathrm{pg} / \mathrm{ml})$ resulted in a higher event probability $(\mathrm{p}<0.01)$. Multivariate Cox hazards analysis showed that higher dopamine levels were a significant and independent risk factor for future coronary events (hazard ratio 3.3, 95\% confidence interval 1.3-8.1, p<0.01). Furthermore, patients with higher dopamine levels had lower left ventricular (LV) ejection fraction and higher levels of brain natriuretic peptide, C-reactive protein, and fibrinogen than those with lower dopamine levels.

Conclusions Plasma levels of free dopamine are increased in association with a decrease in LV function and an increase in inflammatory risk markers. Higher free dopamine levels are an independent risk factor for future coronary events in CAD patients. (Circ J 2007; 71: 688-692)
\end{abstract}

Key Words: Coronary artery disease; Dopamine; Inflammation; Prognosis; Risk factors

I thas been shown that activation of the sympathetic nervous system promotes platelet aggregation and platelet thrombi formation, increases myocardial oxygen demand because of an increase in heart rate, and predisposes to the development of ventricular arrhythmias! ${ }^{1-5}$ Thus, increased levels of plasma norepinephrine, reflecting sympathetic activation to compensate for left ventricular (LV) dysfunction, adversely affect outcomes in patients with myocardial infarction (MI) 6 Although dopamine, a precursor of epinephrine and norepinephrine biosynthesis, has been widely used for the treatment of congestive heart failure, little attention has been paid to the physiological significance of the plasma levels of endogenous dopamine in heart diseases. Peripheral circulating dopamine is derived from 2 main sources: the sympathetic nerves and the adrenal medulla? Plasma levels of endogenous dopamine are increased in patients with congestive heart failure ${ }^{8}$ and in other circumstances in which the sympathoadrenal system is stimulated, such as upright posture, physical exercise stress, and hypoglycemia? However, it is unclear whether plasma levels of free endogenous dopamine may have a predictive value for future cardiovascular events in patients

(Received November 27, 2006; revised manuscript received February 2, 2007; accepted February 21, 2007)

Department of Internal Medicine II, University of Yamanashi, Yamanashi, Japan

Mailing address: Kiyotaka Kugiyama, MD, Department of Internal Medicine II, University of Yamanashi, Faculty of Medicine, 1110 Shimokato, Chuo, Yamanashi 409-3898, Japan. E-mail: kugiyama @ yamanashi.ac.jp with coronary artery disease (CAD). This study assessed the hypothesis that plasma levels of free endogenous dopamine, a biologically active form of dopamine, may provide prognostic information in stable CAD.

\section{Methods}

\section{Study Patients}

This study enrolled 210 consecutive patients with stable CAD who underwent cardiac catheterization for chest pain or ischemic changes detected by electrocardiogram (ECG) on effort at Yamanashi University Hospital from January 2002 to January 2003. All patients had angiographic evidence of organic disease with $>75 \%$ diameter stenosis of at least 1 major coronary artery (1-vessel disease, 91 patients; 2-vessel disease, 66 patients; 3 -vessel disease, 53 patients). None of the patients had had episodes of angina at rest or changes in the frequency of angina and response to sublingual nitroglycerin in the previous 3 months. The exclusion criteria were: acute coronary syndromes, major surgery and trauma or serious infectious diseases within the previous 4 weeks, death before discharge, malignancies, chronic inflammatory diseases, and chronic renal failure (serum creatinine levels $\geq 2.5 \mathrm{mg} / \mathrm{dl}$ ). The baseline characteristics of the study patients are shown in Table 1 . Written informed consent was given by all patients prior to enrollment. The study was approved by the institutional ethics committee and conformed with the principles outlined in the 1975 Declaration of Helsinki. 
Table 1 Comparisons of Clinical Characteristics of Study Patients According to the Free Dopamine Level

\begin{tabular}{|c|c|c|}
\hline & $\begin{array}{c}\text { Dopamine } \\
<30 \mathrm{pg} / \mathrm{ml} \\
(n=105)\end{array}$ & $\begin{array}{c}\text { Dopamine } \\
\geq 30 \mathrm{pg} / \mathrm{ml} \\
(n=105)\end{array}$ \\
\hline Age (years) & $65.8 \pm 11.8$ & $67.6 \pm 11.4$ \\
\hline Male (\%) & 68 & 72 \\
\hline Smoking (\%) & 44 & 46 \\
\hline Hypertension (\%) & 54 & 60 \\
\hline Diabetes mellitus (\%) & 40 & 44 \\
\hline Body mass index $\left(\mathrm{kg} / \mathrm{m}^{2}\right)$ & $23.7 \pm 3.1$ & $23.3 \pm 3.5$ \\
\hline History of $M I(\%)$ & 17 & 20 \\
\hline Total cholesterol $(\mathrm{mg} / \mathrm{dl})$ & $200 \pm 38$ & $196 \pm 34$ \\
\hline$h s C R P(m g / d l)$ & $0.34 \pm 0.67$ & $0.81 \pm 1.06 * *$ \\
\hline Fibrinogen $(\mathrm{mg} / \mathrm{dl})$ & $301 \pm 81$ & $347 \pm 118 * *$ \\
\hline Creatinine $(\mathrm{mg} / \mathrm{dl})$ & $0.91 \pm 0.25$ & $0.95 \pm 0.31$ \\
\hline $\mathrm{CrCl}(\mathrm{ml} / \mathrm{min})$ & $71 \pm 21$ & $67 \pm 26$ \\
\hline No. of diseased coronary arteries & $1.5 \pm 0.7$ & $2.1 \pm 0.8 * *$ \\
\hline \multicolumn{3}{|l|}{ Medication (\%) } \\
\hline$\beta$-blockers & 24 & 21 \\
\hline Calcium channel blockers & 78 & 71 \\
\hline$A C E I$ and/or $A R B$ & 62 & 66 \\
\hline Aspirin & 99 & 98 \\
\hline Statin & 32 & 28 \\
\hline Diuretics & 22 & 26 \\
\hline
\end{tabular}

Data are mean value $\pm S D$ or $\%$ of patients.

${ }^{*} p<0.01$ vs respective values in patients with dopamine $<30 \mathrm{pg} / \mathrm{ml}$.

$M I$, myocardial infarction; hs CRP, high-sensitivity $C$-reactive protein; $\mathrm{CrCl}$, creatinine clearance; ACEI, angiotensin-converting enzyme inhibitor; ARB, angiotensin II receptor blocker.

\section{Measurements of Cardiac Function}

All patients underwent cardiac catheterization, including right heart catheterization, left ventriculography and coronary angiography, in the morning after an overnight fast. The Swan-Ganz catheter technique was used for right heart catheterization, and pulmonary capillary wedge pressure and cardiac index (CI) were measured as in our previous studies! ${ }^{10,11} \mathrm{LV}$ end-systolic and diastolic volume indexes, and LV ejection fraction (EF) were determined from left ventriculograms by the area-length method using computerassisted analysis (Cardio 2000, Fukuda-denshi Corporation, Tokyo, Japan).

\section{Laboratory Examination}

Venous blood samples were obtained from all patients in the morning after a 12-h overnight fast at the time of enrollment in the study. Plasma was stored at $4^{\circ} \mathrm{C}$ and was used for assays of neurohormones within $24 \mathrm{~h}$ of sampling. The serum and the remaining plasma were stored at $-80^{\circ} \mathrm{C}$ until other assays were performed. Plasma levels of free norepinephrine, free epinephrine, and free dopamine were determined by high-performance liquid chromatography with the fluorogenic reagent, diphenylethylenediamine (HLC725 CA II, TOSOH, Tokyo) ${ }^{2}$ Atrial natriuretic peptide (ANP) and brain natriuretic peptide (BNP) concentrations were measured by immunoradiometric assay (Shionogi Co, Osaka, Japan), as described previously!0 High-sensitivity C-reactive protein (hsCRP) levels in the serum were assayed by rate nephelometry (Dade Behring, Marburg, Germany). Fibrinogen levels were determined by the method of Clauss. ${ }^{3}$ The lower detection limit of free dopamine levels was $11 \mathrm{pg} / \mathrm{ml}$. The intra- and inter-assay coefficients of variation for free dopamine were within $2.4 \%$ and $3.4 \%$, respectively. The creatinine clearance was estimated in all patients according to the Cockroft-Gault
Table 2 Comparison of Neurohormone Levels and Hemodynamic Parameters in Patients With Higher and Lower Free Dopamine Levels

\begin{tabular}{lcc}
\hline \hline & $\begin{array}{c}\text { Dopamine } \\
<30 \mathrm{pg} / \mathrm{ml} \\
(\mathrm{n}=105)\end{array}$ & $\begin{array}{c}\text { Dopamine } \\
\geq 30 \mathrm{pg} / \mathrm{ml} \\
(\mathrm{n}=105)\end{array}$ \\
\hline Neurohormonal levels & & \\
Norepinephrine $(\mathrm{pg} / \mathrm{ml})$ & $294 \pm 188$ & $346 \pm 227$ \\
Epinephrine $(\mathrm{pg} / \mathrm{ml})$ & $43 \pm 26$ & $32 \pm 38$ \\
BNP $(\mathrm{pg} / \mathrm{ml})$ & $61.3 \pm 79.9$ & $196.8 \pm 355.9^{* *}$ \\
ANP $(\mathrm{pg} / \mathrm{ml})$ & $33.8 \pm 34.2$ & $53.5 \pm 74.9^{*}$ \\
Hemodynamics parameters & & \\
LVEF $(\%)$ & $63.4 \pm 10.9$ & $50.8 \pm 15.1^{* *}$ \\
LVEDVI $\left(\mathrm{ml} / \mathrm{m}^{2}\right)$ & $80.7 \pm 22.2$ & $96.5 \pm 30.8^{* *}$ \\
LVESVI $\left(\mathrm{ml} / \mathrm{m}^{2}\right)$ & $27.8 \pm 15.2$ & $46.3 \pm 30.5^{* *}$ \\
LVEDP $(\mathrm{mmHg})$ & $12.4 \pm 5.1$ & $15.1 \pm 5.3^{* *}$ \\
CI $\left(\mathrm{L} \cdot \mathrm{min}^{-1} \cdot \mathrm{m}^{-2}\right)$ & $3.4 \pm 1.01$ & $2.7 \pm 0.5^{* *}$ \\
PCWP $(\mathrm{mmHg})$ & $11.1 \pm 3.9$ & $14.1 \pm 5.4^{* *}$ \\
Heart rate $($ beats/min $)$ & $71.5 \pm 15.6$ & $73.2 \pm 17.6$ \\
SBP $(\mathrm{mmHg})$ & $130 \pm 24$ & $131 \pm 26$ \\
DBP $(\mathrm{mmHg})$ & $70 \pm 14$ & $72 \pm 17$ \\
\hline
\end{tabular}

Data are mean value $\pm S D$.

${ }^{*} p<0.05, *^{*} p<0.01$ vs respective values in patients with dopamine $<30 \mathrm{pg} / \mathrm{ml}$.

$B N P$, brain natriuretic peptide; ANP, atrial natriuretic peptide; LVEF, left ventricular ejection fraction; $L V E D V I$, left ventricular end-diastolic volume index; LVESVI, left ventricular end-systolic volume index; LVEDP, left ventricular end-diastolic pressure; $C I$, cardiac index; $P C W P$, pulmonary capillary wedge pressure; SBP, systolic blood pressure; DBP, diastolic blood pressure.

equation ${ }^{14}$ using baseline weight and serum creatinine in each participant. For men, the creatinine clearance was estimated as follows: creatinine clearance $=([140-$ age in years] $\times$ weight in $\mathrm{kg}) /(72 \times$ creatinine $\mathrm{mg} / \mathrm{dl})$. For women, the value of creatinine clearance was multiplied by 0.85 , as specified in the Cockroft-Gault equation.

\section{Follow-up Study}

All study patients were followed up every month at a hospital for a period of up to 36 months or until the occurrence of 1 of the following clinical coronary events: cardiac death, nonfatal MI, recurrent or refractory angina pectoris requiring revascularization, or worsening heart failure requiring re-admission. The time to the first cardiovascular event was evaluated prospectively. The diagnosis of MI required chest pain for $>30 \mathrm{~min}$, appearance of a new $\mathrm{Q}$ wave on the ECG, and elevation of creatine kinase to more than twice the upper limit of normal. Information regarding survival and endpoints was obtained from hospital records, by mail, and by telephone. Cause of death was determined from hospital records. The need for and timing of revascularization were determined by the attending physicians and interventional cardiologists without regard to the study protocol.

\section{Statistical Analysis}

All descriptive data are expressed as the mean value \pm $\mathrm{SD}$ or number of patients (percentage). The mean value and frequency between 2 groups were compared using Student's unpaired t-test and chi-square analysis, respectively. Survival analysis was carried out using the Kaplan-Meier method (log-rank test), according to the presence or absence of higher levels of dopamine $(\geq 30 \mathrm{pg} / \mathrm{ml}$, which was arbitrarily selected based on the $50^{\text {th }}$ percentile of distribution of free dopamine levels in the study patients). Cox proportion- 


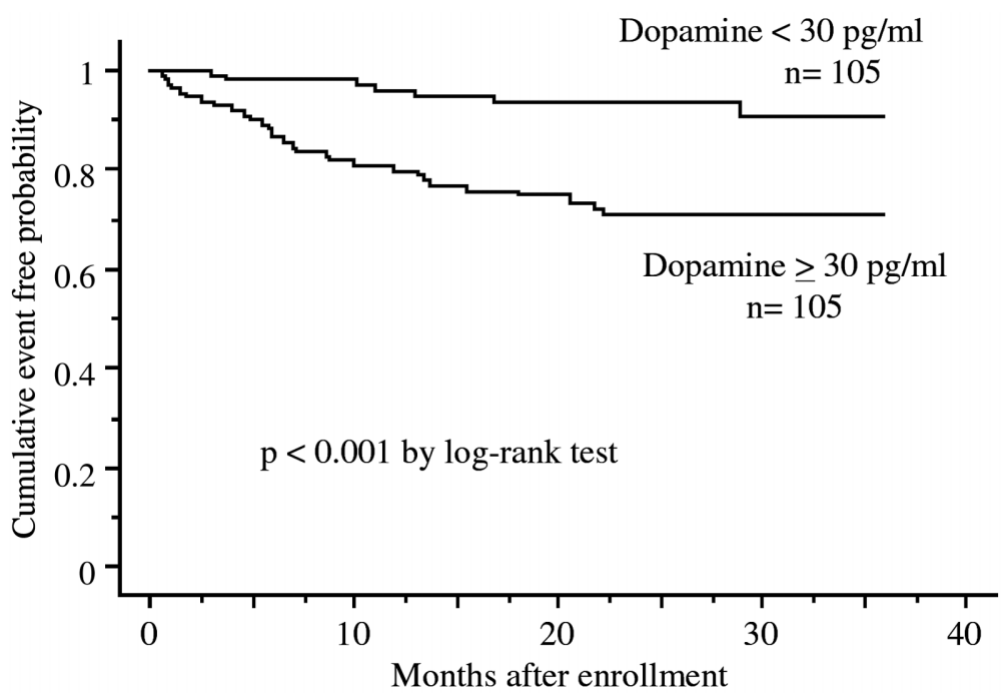

Fig 1. Kaplan-Meier curves comparing the probability of developing clinical coronary events according to free dopamine levels during the follow-up period $(\leq 36$ months after enrollment) in 210 patients with coronary artery disease; $\mathrm{n}=105$ and 105 in the higher $(\geq 30 \mathrm{pg} / \mathrm{ml})$ and lower $(<30 \mathrm{pg} / \mathrm{ml})$ group, respectively.
Table 3 Univariate Cox Hazards Analysis of Risk Factors for Future Coronary Events

\begin{tabular}{lccc}
\hline \hline & $\begin{array}{c}\text { Hazard } \\
\text { ratio }\end{array}$ & $95 \%$ CI & p value \\
\hline Dopamine $(\geq 30 \mathrm{pg} / \mathrm{ml})$ & 4.4 & $1.9-10.0$ & $<0.01$ \\
LVEF $(<40 \%)$ & 2.8 & $1.4-5.3$ & $<0.01$ \\
Diabetes mellitus & 2.6 & $1.3-4.9$ & $<0.01$ \\
3-vessel disease & 2.5 & $1.3-4.8$ & $<0.01$ \\
hsCRP $(\geq 0.3 \mathrm{mg} / \mathrm{dl})$ & 2.3 & $1.2-4.4$ & $<0.05$ \\
BNP $(\geq 68 \mathrm{pg} / \mathrm{ml})$ & 2.2 & $1.1-4.5$ & $<0.05$ \\
Fibrinogen $(\geq 300 \mathrm{mg} / \mathrm{dl})$ & 1.9 & $0.9-3.8$ & $\mathrm{NS}$ \\
ANP $(\geq 51 \mathrm{pg} / \mathrm{ml})$ & 1.7 & $0.9-3.4$ & $\mathrm{NS}$ \\
Hypertension & 1.5 & $0.8-2.9$ & $\mathrm{NS}$ \\
Norepinephrine $(\geq 270 \mathrm{pg} / \mathrm{ml})$ & 1.4 & $0.7-2.7$ & $\mathrm{NS}$ \\
Age $(\geq 70$ years $)$ & 1.2 & $0.6-2.3$ & $\mathrm{NS}$ \\
Creatinine $(\geq 0.92 \mathrm{mg} / \mathrm{dl})$ & 1.2 & $0.6-2.5$ & $\mathrm{NS}$ \\
Hypercholesterolemia $(\geq 220 \mathrm{mg} / \mathrm{dl})$ & 1.1 & $0.5-2.2$ & $\mathrm{NS}$ \\
Smoking & 0.9 & $0.5-1.8$ & $\mathrm{NS}$ \\
Epinephrine $(\geq 30 \mathrm{pg} / \mathrm{ml})$ & 0.9 & $0.5-1.8$ & $\mathrm{NS}$ \\
CrCl $(\geq 60 \mathrm{ml} / \mathrm{min})$ & 0.7 & $0.4-1.3$ & $\mathrm{NS}$ \\
\hline
\end{tabular}

CI, confidence interval. Other abbreviations as in Tables 1 and 2.

al hazards analysis was performed to determine the predictive value for cardiovascular events during the follow-up of the following categorical variables: higher dopamine levels ( $\geq 30 \mathrm{pg} / \mathrm{ml}$ ); age ( $\geq 70$ years); sex (male); smoking history (defined as smoking $>10$ cigarettes/day for $>10$ years); hypertension $(>140 / 90 \mathrm{mmHg}$ or requiring antihypertensive medication); diabetes mellitus (defined according to the American Diabetes Association report ${ }^{15}$ or as taking antidiabetic medication); hypercholesterolemia ( $\geq 220 \mathrm{mg} / \mathrm{dl}$ or the use of lipid-lowering medication); 3-vessel CAD; higher levels of BNP ( $\geq 68 \mathrm{pg} / \mathrm{ml})$; ANP $(\geq 51 \mathrm{pg} / \mathrm{ml})$; epinephrine $(\geq 30 \mathrm{pg} / \mathrm{ml})$; norepinephrine $(\geq 270 \mathrm{pg} / \mathrm{ml})$; fibrinogen $(\geq 300 \mathrm{mg} / \mathrm{dl})$; serum creatinine $(\geq 0.92 \mathrm{mg} / \mathrm{dl})$; creatinine clearance $\left(<60 \mathrm{ml} / \mathrm{min}\right.$ as described previously $\left.{ }^{14}\right)$; and hsCRP $\left(\geq 0.3 \mathrm{mg} / \mathrm{dl}\right.$ as described previously $\left.{ }^{16}\right)$; and lower LVEF $(<40 \%)$. The cut-off points for the higher levels of BNP, ANP, epinephrine, fibrinogen, serum creatinine, and norepinephrine were arbitrarily defined as the $50^{\text {th }}$ percentile of their respective distributions in the study patients. Statistical significance was defined as $\mathrm{p}<0.05$. Analyses were performed partly using Stat View 5.0 for Windows (Tokyo, Japan).

\section{Results}

Comparisons of Baseline Clinical Profiles, Hemodynamics and Neurohormones

The free dopamine levels were under the lower detection limit $(11 \mathrm{pg} / \mathrm{ml})$ in 88 patients $(42 \%)$. Therefore, linear correlation analysis between plasma levels of norepinephrine or epinephrine and dopamine in all of the study patients could not be performed. Among the study patients, 160 patients $(76 \%$ ) had preserved LV function (LVEF $\geq 50 \%$ ). Patients with higher levels of free dopamine $(\geq 30 \mathrm{pg} / \mathrm{ml})$ had higher levels of BNP, ANP, hsCRP, fibrinogen, and more extensive $\mathrm{CAD}$ than those with lower dopamine levels $(<30 \mathrm{pg} / \mathrm{ml})$, as shown in Tables 1 and 2. Norepinephrine levels were not significantly different between patients with and without higher levels of free dopamine. The frequency of cardiac medication use was similar between patients with and without higher levels of free dopamine.

The patients with higher levels of dopamine had lower LVEF and CI and higher LV end-diastolic and systolic volume indexes, LV end-diastolic pressure, and pulmonary capillary wedge pressure than those with lower levels of dopamine, as shown in Table2. Heart rate and systolic and diastolic blood pressures were comparable between patients with and without higher dopamine levels.

Patients with higher levels of norepinephrine $(\geq 270 \mathrm{pg} / \mathrm{ml})$ had no significant difference in hsCRP and fibrinogen levels, LVEF, and CI compared with those without higher norepinephrine levels (hsCRP levels, $0.61 \pm 0.99$ vs $0.57 \pm$ $0.86 \mathrm{mg} / \mathrm{dl}$, respectively; fibrinogen levels, $332.3 \pm 114.6 \mathrm{vs}$ $318.8 \pm 94.3 \mathrm{mg} / \mathrm{dl}$, respectively; LVEF, $55.7 \pm 14.8$ vs $58.0 \pm$ $14.7 \%$, respectively; CI, $2.8 \pm 0.6$ vs $3.1 \pm 0.9 \mathrm{~L} \cdot \mathrm{min}^{-1} \cdot \mathrm{m}^{-2}$, respectively, all $\mathrm{p}=\mathrm{NS}$ ).

\section{Relationship of High Plasma Levels of Free Dopamine With Future Coronary Events in Patients With CAD}

All of the study patients completed the follow-up study (from 1 to 36 months, mean $22 \pm 9.6$ months). All these patients received the standardized medical therapy outlined in Table 1. During the follow-up period, events occurred in 30 patients with higher dopamine levels $(\geq 30 \mathrm{pg} / \mathrm{ml})$ and in 7 patients with lower dopamine levels $(<30 \mathrm{pg} / \mathrm{ml})(5$ and 1 patients with cardiac death, 8 and 2 nonfatal MI, 14 and 3 recurrent or refractory angina pectoris requiring revascularization, and 3 and 1 worsening heart failure requiring 
re-admission, respectively). Kaplan-Meier survival analysis demonstrated a significantly higher probability of developing a clinical event in the patients with the higher levels of free dopamine than in those with the lower levels (Fig 1). In the univariate Cox proportional hazards model, higher levels of free dopamine, lower LVEF, the presence of diabetes and 3-vessel disease, and higher levels of hsCRP and BNP were significant predictors of clinical coronary events (Table 3 ). In the multivariate Cox proportional hazards model, higher levels of free dopamine remained significant in association with future coronary events after adjustment for potential confounders including lower LVEF, higher levels of BNP and norepinephrine (Table 4). In contrast, higher norepinephrine levels $(\geq 270 \mathrm{pg} / \mathrm{ml})$ were not a significant predictor in either univariate or multivariate analysis (Tables 3,4).

\section{Discussion}

This is the first study to show that higher levels of free dopamine are a risk marker of future coronary events in patients with stable CAD. Furthermore, patients with higher dopamine levels had a decrease in indexes of LV function and an increase in the levels of BNP and ANP, as compared with those with lower dopamine levels. Therefore, free dopamine levels are increased in proportion to LV dysfunction; therefore, free dopamine levels may be related to LV function in patients with stable CAD.

Dopamine is secreted from sympathetic nerve endings and the adrenal gland ${ }^{7}$ and then rapidly inactivated by conversion to a conjugated form in plasma?,17 Because circulating dopamine is present almost entirely ( $>98 \%)$ in the conjugated form, 7,9 plasma levels of free dopamine (ie, biologically active dopamine) are mainly determined by the net balance between its conjugation and deconjugation by phenol sulfotransferase and arylsulfatase, respectively9, ${ }^{9} 18-20$ Although the precise regulatory mechanisms for the activity of these enzymes remain unclear, the deconjugation of conjugated dopamine to free dopamine is known to increase in patients with chronic heart failure ${ }^{21}$ in whom sympathetic activation occurs chronically. This finding is compatible with previous reports ${ }^{9,22}$ showing that plasma free dopamine levels are increased by sympathetic nervous activation. The circulating concentration of conjugated dopamine is the highest among the concentrations of the circulating catecholamines, usually 5 - to 10 -fold higher than all others, conjugated or free norepinephrine and epinephrine? ${ }^{21,22}$ Therefore, free dopamine levels are greatly influenced by the deconjugation of conjugated dopamine, and this conjugation is also stimulated by cortisol ${ }^{23}$ which is released in the condition of heart failure. Furthermore, the transient increase in free dopamine levels after physiological stress is less as compared with norepinephrine?2 In this context, free dopamine levels may reflect well the steady state of cardiovascular compensation in patients with heart failure.

A number of studies have shown that plasma norepinephrine levels are increased in proportion to LV dysfunction and provide prognostic information whether the etiology of the dysfunction is ischemic or non-ischemic 24 However, few reports have shown the prognostic value of plasma norepinephrine levels in patients with CAD and preserved LV function. Most of the present patients with CAD had preserved LV function (LVEF $\geq 50 \%$ ), which may account for the relatively lower plasma norepinephrine levels in this study compared with patients with LV dysfunction in previ-
Table 4 Multivariate Cox Hazards Analysis of Risk Factors for Future Coronary Events

\begin{tabular}{lccc}
\hline \hline & $\begin{array}{c}\text { Hazard } \\
\text { ratio }\end{array}$ & $95 \%$ CI & p value \\
\hline Dopamine $(\geq 30 \mathrm{pg} / \mathrm{ml})$ & 3.3 & $1.3-8.1$ & $<0.01$ \\
LVEF $(<40 \%)$ & 1.5 & $0.7-3.1$ & $\mathrm{NS}$ \\
BNP $(\geq 68 \mathrm{pg} / \mathrm{ml})$ & 1.3 & $0.6-2.8$ & $\mathrm{NS}$ \\
Norepinephrine $(\geq 270 \mathrm{pg} / \mathrm{ml})$ & 1.2 & $0.6-2.4$ & $\mathrm{NS}$ \\
\hline
\end{tabular}

Abbreviations as in Tables 2 and 3.

ous reports:5,26 Moreover, it is known that plasma norepinephrine levels are variable in the same individual and are transiently increased (nearly 5 -fold) in response to physiological or emotional stress, independently of LV function. ${ }^{27}$ In fact, cardiac hemodynamic parameters were comparable between patients with and without higher norepinephrine levels in the present study. Thus, norepinephrine levels are unlikely to reflect LV function in patients with relatively preserved LV function, accounting for the lack of significant predictive value of norepinephrine levels in the present study. In contrast, the patients with higher free dopamine levels had a decrease in indexes of LV function compared with those with lower dopamine levels. Furthermore, levels of hsCRP and fibrinogen, inflammatory risk factors for future coronary events, ${ }^{28,29}$ were increased in the present study in patients with higher than lower levels of free dopamine, while these inflammatory markers were not increased in patients with higher norepinephrine levels. The intimate association of free dopamine levels with these established inflammatory risk factors may also account for the predictive value of free dopamine levels in the present patients with CAD.

Dopamine causes platelet aggregation and coronary vasoconstriction, $, 2,30$ both of which play an important role in the pathogenesis of coronary plaque instability leading to coronary events. Moreover, an increased plasma concentration of dopamine may be related to the occurrence of ventricular arrhythmias? Although the plasma levels of free dopamine in the present study were too low to exert any significant biological effects, ${ }^{31}$ tissue concentrations of free dopamine may be potentially increased on the basis of extremely high concentrations of norepinephrine in the vascular tree and ischemic myocardium 32 However, it remains to be determined whether higher levels of free dopamine are only a surrogate marker or a mediator of coronary plaque instability. A trial using a dopamine-receptor blocker in a large number of study patients may be required to assess the precise role of free dopamine in the pathogenesis of CAD.

In conclusion, high plasma levels of free dopamine are an independent risk factor for future coronary events in stable CAD patients.

\section{Acknowledgments}

This study was supported by Grants-in-Aid for (B) (2)-15390244, Priority Areas (C) "Medical Genome Science 15012222" from the Ministry of Education, Culture, Sports, Science, and Technology, Health and Labor Sciences Research Grants for Comprehensive Research on Aging and Health (H15-Choju-012), Tokyo, Japan.

\section{References}

1. Anfossi G, Massucco P, Mularoni E, Cavalot F, Burzacca S, Mattiello L, et al. Studies on the effect of dopamine on the human platelet response. Clin Exp Pharmacol Physiol 1992; 19: 613-618. 
2. Braunstein KM, Sarji KE, Kleinfelder J, Schraibman HB, Colwell JA, Eurenius K. The effects of dopamine on human platelet aggregation, in vitro. J Pharmacol Exp Ther 1977; 200: 449-457.

3. Anderson KP. Sympathetic nervous system activity and ventricular tachyarrhythmias: Recent advances. Ann Noninvasive Electrocardiol 2003; 8: 75-89.

4. Oyama N, Urasawa K, Kaneta S, Sakai H, Saito T, Takagi C, et al. Chronic beta-adrenergic receptor stimulation enhances the expression of G-protein coupled receptor kinases, GRK2 and GRK5, in both the heart and peripheral lymphocytes. Circ J 2005; 69: 987-990.

5. Nonomura M, Nozawa T, Matsuki A, Nakadate T, Igarashi N, Kato $\mathrm{B}$, et al. Ischemia-induced norepinephrine release, but not norepinephrine-derived free radicals, contributes to myocardial ischemiareperfusion injury. Circ J 2005; 69: 590-595.

6. McAlpine HM, Cobbe SM. Neuroendocrine changes in acute myocardial infarction. Am J Med 1988; 84: 61-66.

7. Snider SR, Kuchel O. Dopamine: An important neurohormone of the sympathoadrenal system: Significance of increased peripheral dopamine release for the human stress response and hypertension. Endocr Rev 1983; 4: 291-309.

8. Viquerat CE, Daly P, Swedberg K, Evers C, Curran D, Parmley $\mathrm{WW}$, et al. Endogenous catecholamine levels in chronic heart failure: Relation to the severity of hemodynamic abnormalities. Am J Med 1985; 78: 455-460.

9. Van Loon GR. Plasma dopamine: Regulation and significance. Fed Proc 1983; 42: 3012-3018.

10. Nakagawa K, Umetani K, Fujioka D, Sano K, Nakamura T, Kodama $\mathrm{Y}$, et al. Correlation of plasma concentrations of B-type natriuretic peptide with infarct size quantified by tomographic thallium-201 myocardial scintigraphy in asymptomatic patients with previous myocardial infarction. Circ J 2004; 68: 923-927.

11. Kodama Y, Kitta Y, Nakamura T, Takano H, Umetani K, Fujioka D, et al. Atorvastatin increases plasma soluble Fms-like tyrosine kinase1 and decreases vascular endothelial growth factor and placental growth factor in association with improvement of ventricular function in acute myocardial infarction. J Am Coll Cardiol 2006; 48: 43 50.

12. Yoshimura M, Komori T, Nakanishi T, Takahashi H. Estimation of sulphoconjugated catecholamine concentrations in plasma by highperformance liquid chromatography. Ann Clin Biochem 1993; 30: $135-141$.

13. Clauss A. Rapid physiological coagulation method in determination of fibrinogen. Acta Haematol 1957; 17: 237-246.

14. Dries DL, Exner DV, Domanski MJ, Greenberg B, Stevenson LW. The prognostic implications of renal insufficiency in asymptomatic and symptomatic patients with left ventricular systolic dysfunction. J Am Coll Cardiol 2000; 35: 681-689.

15. Expert Committee on the Diagnosis and Classification of Diabetes Mellitus. Report of the expert committee on the diagnosis and classification of diabetes mellitus. Diabetes Care 2003; 26: S5-S20.

16. Pearson TA, Mensah GA, Alexander RW, Anderson JL, Cannon RO 3rd, Criqui M, et al. Centers for Disease Control and Prevention; American Heart Association. Markers of Inflammation and Cardiovascular Disease: Application to Clinical and Public Health Practice:
A Statement for Healthcare Professionals from the Centers for Disease Control and Prevention and the American Heart Association. Circulation 2003; 107: 499-511.

17. Kopin IJ. Catecholamine metabolism: Basic aspects and clinical significance. Pharmacol Rev 1985; 37: 333-364.

18. Ozawa Y, Yoshizumi M, Inui D, Tsuchiya K, Houchi H, Tamaki T, et al. Plasma levels of free and sulfoconjugated catecholamines in patients with atherosclerosis. Biol Pharm Bull 1999; 22: 657-659.

19. Wang PC, Buu NT, Kuchel O, Genest J. Conjugation patterns of endogenous plasma catecholamines in human and rat: A new specific method for analysis of glucuronide-conjugated catecholamines. J Lab Clin Med 1983; 101: 141-151.

20. Huq AH, Matsuoka S, Kurahashi Y, Kuroda Y, Ma SJ, Ohuchi T, et al. Dopamine 4-sulfate: Effects on isolated perfused rat heart and role of atria. Life Sci 1988; 43: 1599-1606.

21. Yoshizumi M, Ishimura Y, Masuda Y, Ohuchi T, Katoh I, Houchi H, et al. Physiological significance of plasma sulfoconjugated dopamine: Experimental and clinical studies. Hypertens Res 1995; 18: S101S106.

22. Dobnig H, Leb G, Lipp R, Porta S, Dusleag J, Eber B, et al. Sulfoconjugated and free plasma catecholamine levels at rest and during exercise in patients with idiopathic dilated cardiomyopathy. Eur $J$ Endocrinol 1995; 132: $181-191$.

23. Kostulak A. The effect of ACTH and cortisone on the behaviour of arylsulphatases in the salivary glands of white rat. Acta Histochem 1977; 58: $63-67$.

24. Benedict CR, Shelton B, Johnstone DE, Francis G, Greenberg B, Konstam M, et al. Prognostic significance of plasma norepinephrine in patients with asymptomatic left ventricular dysfunction: SOLVD investigators. Circulation 1996; 94: 690-697.

25. Cohn JN, Levine TB, Olivari MT, Garberg V, Lura D, Francis GS, et al. Plasma norepinephrine as a guide to prognosis in patients with chronic congestive heart failure. N Engl J Med 1984; 311: 819-823.

26. Isnard R, Pousset F, Trochu J, Chafirovskaia O, Carayon A, Golmard $\mathrm{J}$, et al. Prognostic value of neurohormonal activation and cardiopulmonary exercise testing in patients with chronic heart failure. Am J Cardiol 2000; 86: 417-421.

27. Carruthers M, Conway N, Somerville W, Taggart P, Bates D. Validity of plasma-catecholamine estimations. Lancet 1970; 1: 62-67.

28. Libby P, Ridker PM. Inflammation and atherosclerosis: Role of Creactive protein in risk assessment. Am J Med 2004; 116: 9s - 16s.

29. Mora S, Rifai N, Buring JE, Ridker PM. Additive value of immunoassay-measured fibrinogen and high-sensitivity C-reactive protein levels for predicting incident cardiovascular events. Circulation 2006; 114: 381-387.

30. Crea F, Chierchia S, Kaski JC, Davies GJ, Margonato A, Miran DO, et al. Provocation of coronary spasm by dopamine in patients with active variant angina pectoris. Circulation 1986; 74: 262-269.

31. Lokhandwala MF, Barrett RJ. Cardiovascular dopamine receptors: Physiological, pharmacological and therapeutic implications. J Auton Pharmacol 1982; 2: 189-215.

32. Schomig A, Richardt G. Cardiac sympathetic activity in myocardial ischemia: Release and effects of noradrenaline. Basic Res Cardiol 1990; 85: 9-30. 